\title{
Pound per Gallon
}

National Cancer Institute

\section{Source}

National Cancer Institute. Pound per Gallon. NCI Thesaurus. Code C69102.

A unit of mass concentration defined as the concentration of one pound of a substance in unit volume of the mixture equal to one gallon. The concept also refers to the unit of mass density (volumic mass) defined as the density of substance which mass equal to one pound occupies the volume one gallon. 